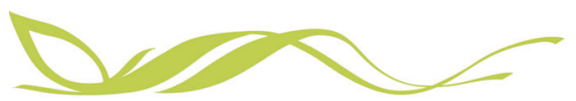

COMMUNICATIONS

EARTH\&ENMRONMENT

ARTICLE

https://doi.org/10.1038/s43247-020-00079-2 OPEN

\title{
Advanced analysis of satellite data reveals ground deformation precursors to the Brumadinho Tailings Dam collapse
}

Stephen Grebby (iD ${ }^{1 凶}$, Andrew Sowter ${ }^{2}$, Jon Gluyas ${ }^{3}$, David Toll (iD ${ }^{4}$, David Gee ${ }^{1}$, Ahmed Athab $^{1}$ \& Renoy Girindran (1D 5

Catastrophic failure of a tailings dam at an iron ore mine complex in Brumadinho, Brazil, on 25th January 2019 released 11.7 million $\mathrm{m}^{3}$ of tailings downstream. Although reportedly monitored using an array of geotechnical techniques, the collapse occurred without any apparent warning. It claimed more than 200 lives and caused considerable environmental damage. Here we present the Intermittent Small Baseline Subset (ISBAS) technique on satellite-based interferometric synthetic aperture radar (InSAR) data to assess the course of events. We find that parts of the dam wall and tailings were experiencing deformation not consistent with consolidation settlement preceding the collapse. Furthermore, we show that the timing of the dam collapse would have been foreseeable based on this observed precursory deformation. We conclude that satellite-based monitoring techniques may help mitigate similar catastrophes in the future.

\footnotetext{
${ }^{1}$ Nottingham Geospatial Institute, Faculty of Engineering, University of Nottingham, Nottingham NG7 2TU, UK. ${ }^{2}$ Terra Motion Limited, Nottingham NG7 2TU, UK. ${ }^{3}$ Durham Energy Institute \& Department of Earth Sciences, Durham University, Durham DH1 3LE, UK. ${ }^{4}$ Department of Engineering, Durham University, Durham DH1 3LE, UK. ${ }^{5}$ School of Geography, University of Nottingham, Nottingham NG7 2RD, UK. ${ }^{凶}$ email: stephen.grebby@nottingham.ac.uk
} 
$\mathrm{T}$ he collapse of Dam I at the Córrego do Feijão iron ore mine complex in Minas Gerais, Brazil, on 25 January 2019 caused a catastrophic mudflow that resulted in the death of more than 200 people and affected the whole region's ecosystem ${ }^{1}$. Dam I, constructed using the upstream method, contained some 11.7 million $\mathrm{m}^{3}$ of tailings and was inactive having not been used for tailings disposal after 2015 (ref. ${ }^{2}$ ).

Despite passing stability tests just months prior $^{3}$, video footage of the moment of collapse suggests the dam underwent a sudden failure that extended across the full $720 \mathrm{~m}$ width and $86 \mathrm{~m}$ height of the dam ${ }^{4}$. The report of the expert panel ${ }^{5}$ suggests that the cause of Dam I collapse was the result of a flow (static) liquefaction mechanism, resulting from internal creep combined with the loss of suction induced by heavy rainfall during the annual wet season (from about October 2018 to the time of the failure). Therefore, information on the deformation of the dam prior to the collapse is crucial to understanding the cause and nature of the collapse. An enhanced understanding can subsequently aid the design of a more effective monitoring framework for the many dams of the same type worldwide, and thus help to mitigate the risk posed by similar future catastrophes.

The dam was being monitored using a combination of methods, including the use of survey monuments, inclinometers, piezometers and ground-based radar, although none of these were reported to have shown significant deformations or any other precursors to failure ${ }^{5}$. With direct access to the monitoring data not readily available, we studied ground surface displacements over Dam I in the 17 months preceding the collapse using satellite interferometric synthetic aperture radar (InSAR). A variety of InSAR techniques are widely used in the measurement of land surface motion, including the relatively recent application to monitoring tailings impoundments ${ }^{6,7}$. Several of these techniques have been used to reveal large displacements rates of up to $-25 \mathrm{~cm} /$ year at the rear of the Dam I tailings beach ${ }^{8,9}$ (also see Supplementary Fig. 1) and more subtle displacement rates $(-25 \mathrm{~mm} /$ year $)$ nearer the centre of the beach during the year preceding the collaps $\mathrm{e}^{10}$, although the observed deformation trends appear consistent with consolidation settlement. The ability to effectively detect precursory accelerating displacements in these cases could have been limited by a lack of measurements and degraded accuracy over the vegetated dam surface, as is common for many conventional InSAR techniques owing to poor coherence ${ }^{11,12}$. In this study, an advanced method, called the Intermittent Small Baseline Subset (ISBAS) technique ${ }^{13}$, was applied to synthetic aperture radar (SAR) images acquired by Europe's Sentinel-1 mission with the aim of detecting any anomalous deformation that may have occurred prior to the collapse of Dam I. The ISBAS technique is a coherent scatterer technique-as opposed to the more common permanent scatterers technique-and was employed as it has been demonstrated to overcome the major InSAR limitation of obtaining sufficient spatial coverage at millimetre-level accuracy over bare soils and vegetated surfaces $^{14}$. Moreover, ISBAS is a multi-temporal stacking technique, which helps to eliminate the contribution of the atmospheric component to the observed phase difference and subsequent ground displacement measurements ${ }^{15-17}$.

The data used are freely available Sentinel-1 C-band SAR imagery. Two overlapping image stacks acquired from adjacent descending orbit tracks (tracks 53 and 155) during the period August 2017 to January 2019 were processed to provide independent observations. With a 12-day revisit time over the site (increased to 6 days over Europe), the processing of these Sentinel-1 stacks provides a synoptic view of any precursory deformation within Dam I to be resolved at high temporal resolution.

\section{Results and discussion}

Deformation of the dam. Firstly, average line-of-sight (LOS) rates of motion were derived for each track using the ISBAS technique (Methods). Data from both tracks indicate widespread ground surface displacements across the dry, vegetated tailings beach behind the dam wall for the period 2017-2019 (Fig. 1); this deformation is not adequately detected using a conventional Small Baseline Subset (SBAS) approach (Supplementary Fig. 2), which provides only $3.3 \%$ coverage of the entire dam structure compared with $99.5 \%$ using ISBAS. The stack for track 53 reveals LOS displacement velocities typically between $-7 \mathrm{~mm} /$ year and $-6 \mathrm{~mm} /$ year (i.e., downward/westward motion) over the central area of the tailings beach, with displacement greatest immediately behind the crest at rates of up to $-8 \mathrm{~mm} /$ year (Fig. 1b). A similar displacement pattern is observed for the adjacent track to the east (track 155), with the majority of LOS velocities between $-6 \mathrm{~mm} /$ year and $-5 \mathrm{~mm} /$ year over central parts of the tailings beach and up to $-6 \mathrm{~mm} /$ year behind the crest (Fig. 1c). The difference in the magnitudes of LOS velocities over the dam structure between the two tracks can be primarily attributed to the variation in their incidence angles (Fig. 1e). This is because larger incidence angles $\left(45^{\circ}\right.$ for track 155 vs. $32^{\circ}$ for track 53$)$ are less sensitive for detecting the vertical component of motion in the LOS direction, subsequently leading to an underestimation of the velocity. Irrespective of some minor noise likely due to residual atmospheric effects on the periphery, the consistency of the observed patterns over the dam structure between the two independent displacement maps provides verification that the tailings were prone to some form of deformation within the 17-month period before the collapse.

Average rates of motion provide useful information regarding summative trends during a specified time interval, and in this case prove consistency between the two sets of observations. However, in many cases, landscape evolution is nonlinear ${ }^{18}$. Therefore, a time-series of surface motion was extracted independently for each track ${ }^{19}$, enabling further investigation of the deformation history of Dam I over the observed period ${ }^{20}$. The results illustrate that some distinctive deformations observed on the dam wall, and front and back of the tailings beach were indeed nonlinear (Fig. 2). The time-series analysis also reveals the spatial evolution of the deformation. This analysis reveals that between August 2017 and 17 January 2019 widespread cumulative LOS displacement in the region of $-6 \mathrm{~mm}$ is observed across most of the tailings beach for track 155, with a maximum displacement of up to $-15 \mathrm{~mm}$ confined to a point towards the back-centre of the beach at location 3 (Fig. 2a). The time-series reveals that most of this cumulative LOS displacement occurred quite rapidly from December 2018 onwards, following what appears to have been a 10-month period of very slow settlement (Fig. 2c; location 3). A consistent amount of displacement is also observed at the corresponding location from the adjacent track, with the time-series for location 6 also showing a 10-month period of slow settlement prior to a somewhat sudden displacement, albeit slightly earlier in midNovember 2018 (Fig. 2b, c). The onset of the accelerated deformation at the back of the tailing beach is strongly correlated with increased rainfall between mid-October and mid-December 2018 (Fig. 2c). Differences in the pattern and timing of the onset deformation between the two tracks are most likely attributable to a combination of factors associated with the offset in the timing of the image acquisitions between tracks, the effect of which will be amplified during the period of increasingly dynamic deformation preceding the failure. At the front of the tailings beach (location 5), deformation is widespread across the central portion, with several patches experiencing greater cumulative LOS displacement on the order of $-18 \mathrm{~mm}$ for 

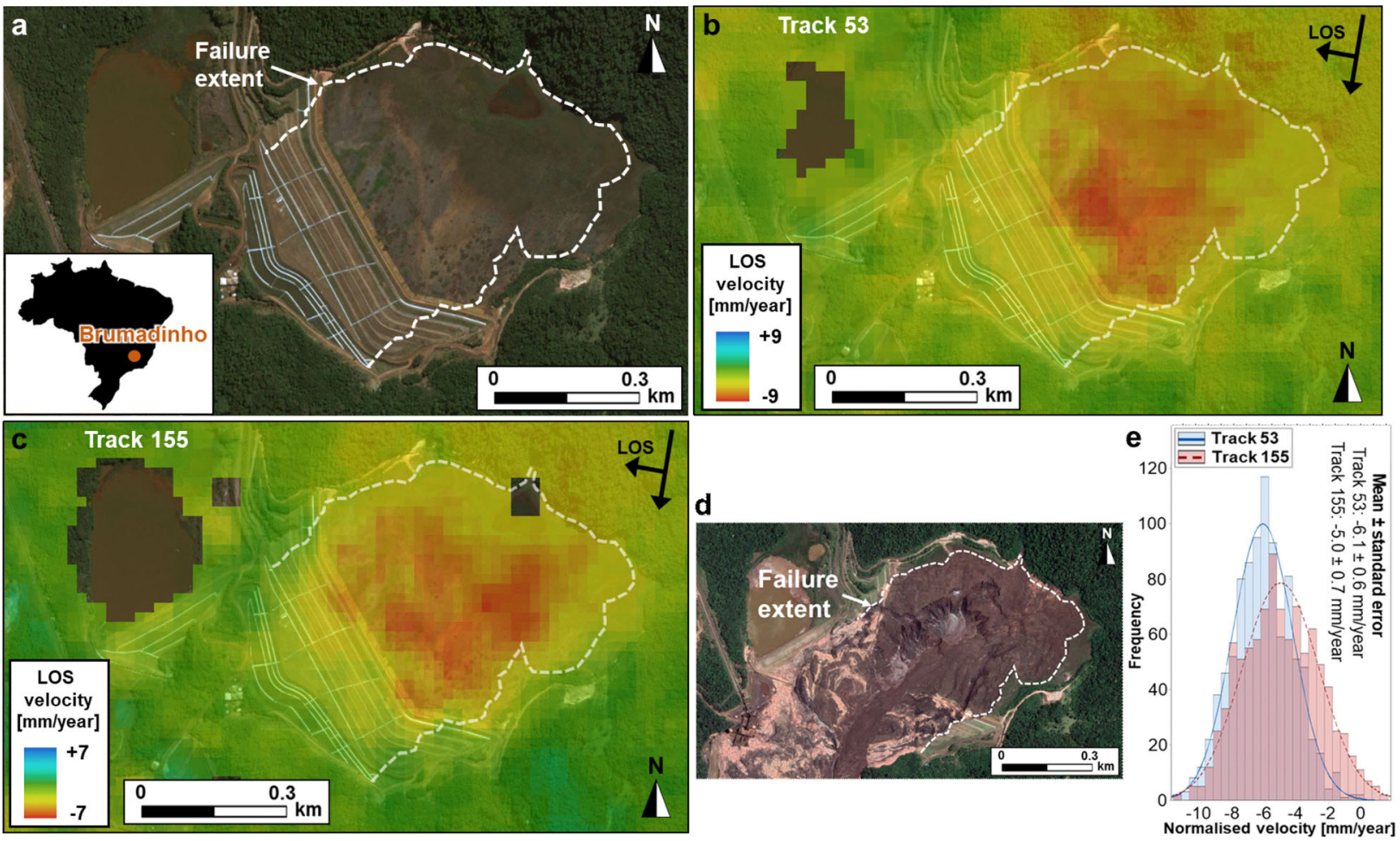

Fig. 1 Location and deformation of the Brumadinho tailings dam, Brazil $\left(\mathbf{2 0 . 1 2}^{\circ} \mathrm{S}, \mathbf{4 4 . 1 2}^{\circ} \mathbf{W}\right)$. a Map showing the location and failure extent (white dashed line) of the dam collapse. $\mathbf{b}$ InSAR-derived average line-of-sight (LOS) rate of ground surface deformation for August $2017-J a n u a r y ~ 2019$ from track 53, and $\mathbf{c}$ track 155. d Post-collapse image of the dam. e Comparison of the incidence angle-normalised LOS velocities of the dam between the two tracks. Negative LOS velocities indicate motion away from the satellite. Basemap images (c) 2020 Maxar Technologies.

August 2017-22 January 2019 (Fig. 2b). This widespread LOS deformation at the front of the beach (location 2) is also captured from track 155 (Fig. 2a). Overall, the time-series reveals that the deformation at locations 2 and 5 developed quasi-linearly (Fig. 2c), reducing with time, which is typical of consolidation settlement of tailings impoundments ${ }^{21}$. However, a sudden change in the rate of displacement is observed at location 5 between the last two observations made just prior to the dam failure (10 January-22 January 2019).

There is no evidence of significant or sustained deformation in the centre of the dam wall (location 1) between August 2017 and 17 January 2019 (Fig. 2a), although some weak $(\sim \pm 2 \mathrm{~mm})$ periodical displacement is apparent (Fig. 2c). This fluctuating minor deformation is on a $\sim 9$-month cycle that is in phase with the main rainy season, probably representing an elastic response of the dam wall to seasonal ground water level variation and associated pore pressure change in the tailings impoundment ${ }^{21}$. Piezometer data corroborate this by showing short-term changes in the water level in the lower part of the dam that coincide with the rainy season ${ }^{5}$. The analysis for track 53 shows two arms of deformation extending down either side of the front of the dam wall (Fig. 2b), which coincide with the extent of the failure. The deformation is greatest on the right toe of the dam wall (looking towards the dam) at location 4 , where the cumulative displacement is on the order of $-18 \mathrm{~mm}$ in the LOS. Based on the timeseries, this area was largely stable prior to subtle deformation in mid-October 2018 following an increase in rainfall, and then a subsequent accelerated displacement into January 2019 just 2 weeks prior to the collapse (Fig. 2c; location 4).

Consolidation settlement of the tailings would be expected to reduce with time as water is removed from the tailings. This is evident from the early trends at most of the presented locations, where there is initial downward/westward movement that reduces with time, approaching a period of stability that suggests consolidation was either complete or nearing completion. However, the sudden accelerated displacements established at locations 3, 4, 5 and 6 from the latter part of October 2018 to January 2019 cannot be explained by a consolidation process. There is the possibility that the rate could accelerate during a period of drying, as evapo-transpiration from the ground surface could induce additional consolidation settlements. However, the increased rate of displacement is associated with wetting periods rather than drying periods. This implies that the deformations are associated with infiltration and wetting of the soils, leading to reduction in suction at the surface of the tailings ${ }^{5}$ and hence reduction in soil strength. It is therefore likely that the short periods of observed accelerated deformation would contribute to internal strains (described as internal creep by the report of the expert panel ${ }^{5}$ ) that could induce static liquefaction in the brittle materials, eventually culminating in the collapse of the tailings dam.

As we have satellite observations from two different positions in orbit, it is possible to perform a stereo analysis in order to resolve the LOS motion into east-west and up-down components for a comprehensive contextual evaluation of the site. Unlike optical satellite and photogrammetric techniques, the ability to resolve the two components between two SAR images is dictated by the difference in incidence angle, rather than orbital baseline ${ }^{22}$. The optimum accuracy is achieved when the angular separation is small in terms of opposite-side stereo pairs, and large for same-side pairs. Although opposite-side SAR pairs offer the most accurate results, they are normally considered unsuitable for stereo applications owing to illumination differences and overwhelming layover, shadow and foreshortening 

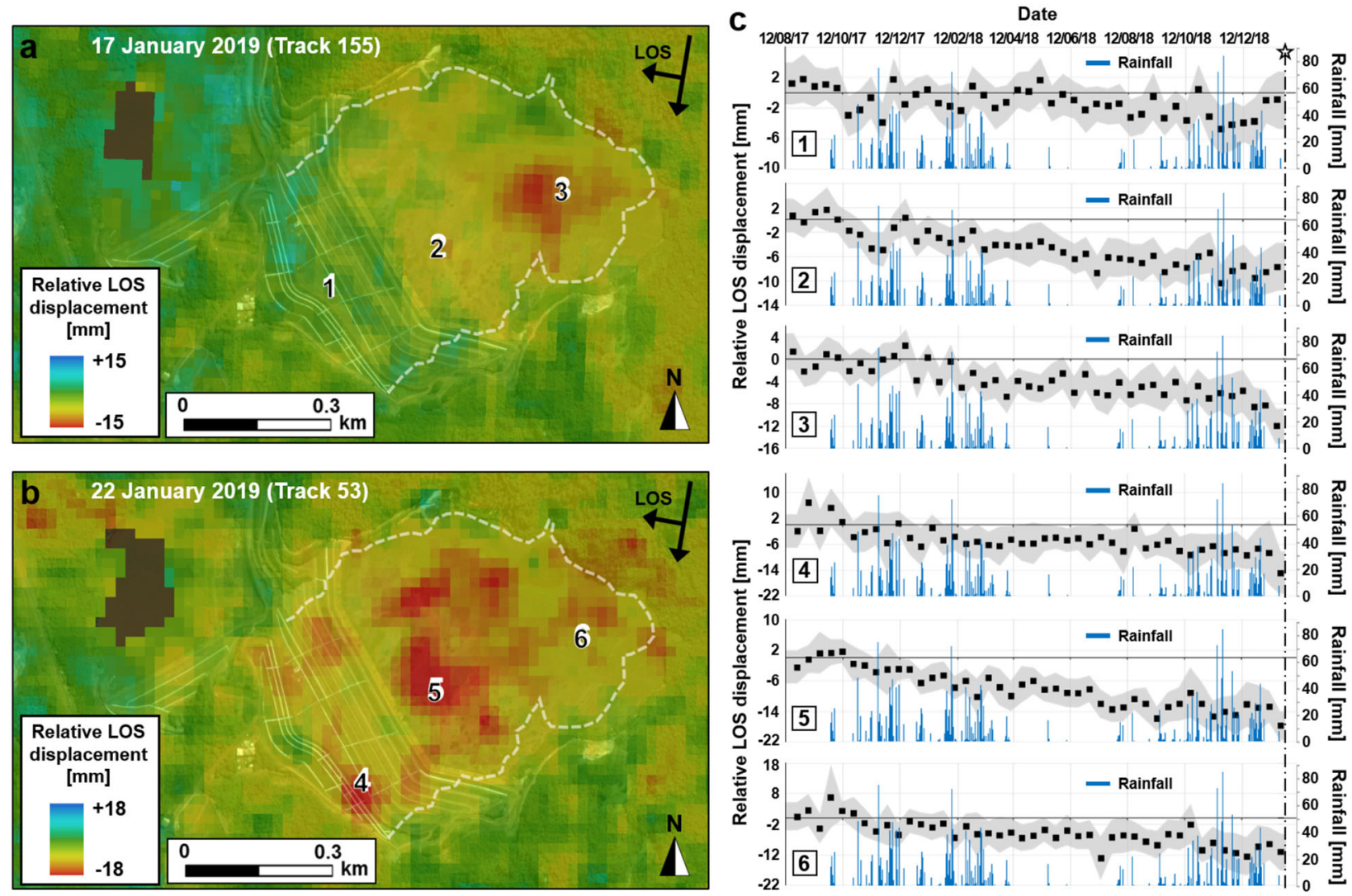

Fig. 2 Time-series of InSAR-derived deformation of the Brumadinho tailings dam. a Cumulative LOS displacement between August 2017 and 17 January 2019 (from track 155), and $\mathbf{b} 22$ January 2019 (from track 53). Negative LOS displacements indicate motion away from the satellite. White dashed line represents the failure extent of the dam. c Time-series of mean LOS displacement at locations 1-6 indicated on $\mathbf{a}$, $\mathbf{b}$, and daily rainfall. Grey shading represents the cumulative uncertainty of the standard error of the ISBAS solutions plus the standard deviation of the LOS displacements observed at each location. The star and vertical dashed line indicate the occurrence of the dam collapse on 25 January 2019. Basemap image (c) 2020 Maxar Technologies.

effects in the presence of topography ${ }^{23}$. As a consequence, it is far more common for radargrammetric surveys to use same-side pairs. For this site, the Sentinel-1 mission acquires only sameside data from descending passes, which allows for a same-side stereo analysis using the overlapping tracks 53 and 155 . However, an angular difference in the geometries of only $\sim 13^{\circ}$ between tracks limits the ability to determine the motion components to only a low level of accuracy. For example, a typical LOS accuracy of $2 \mathrm{~mm}$ in each case would amplify to 4 $\mathrm{mm}$ in up-down and $6 \mathrm{~mm}$ in east-west directions respectively, which, given the low rates of motion detected, may not be sufficient to determine small changes in the direction of motion on the dam itself. Nonetheless, the stereo analysis indicates that the deformation observed on the dam wall and front and back of the tailings dam in the LOS is predominantly in the vertical direction (Supplementary Fig. 3). This is in agreement with the findings of the expert panel report $^{5}$.

Timing of the dam collapse. The InSAR time-series for locations on key features of the dam exhibiting accelerated deformation characteristics (locations 3, 4, 5 and 6; see Fig. 2) were subjected to the well-established inverse velocity analysis ${ }^{24}$, in order to determine whether effective estimates of the date of the failure would have been possible ${ }^{25}$. Performed on velocities derived from displacement observations for the period corresponding to the final acceleration phase ${ }^{26}$, the analysis predicts a time interval for when the dam failure was expected to occur. In this case, we are identifying an acceleration of internal movements that are thought to be sufficient to induce the static liquefaction mechanism that caused the collapse. This is based on the observations of the expert panel that the tailings showed brittle strength loss due to their bonded nature and that very small strains were sufficient to reach peak strength ${ }^{5}$. The back-analysis of the observed deformation enabled a forecast of the collapse time interval for location 3 of 513 to 537 days after the initial InSAR observation (made on 19 August 2017), 512 to 537 days for location 4,515 to 527 days for location 5 , and 523 to 551 days for location 6 (Fig. 3a, b). The dam collapse occurred 524 days into the monitoring period, meaning that the failure date was within every one of the ranges forecasted using the InSAR observations at all four locations. We also performed a sensitivity analysis to determine how early and reliably a correct collapse date might have been predicted if the dam had been subject to systematic monitoring using the Sentinel-1 InSAR measurements. From this (Fig. 3c), we see that the correct time interval may have been forecastable as early as 75 days before the collapse (i.e., 11 November 2018) based on the InSAR-derived velocity measurements for location 6 . However, it would not have been possible to predict a correct failure date by incorporating the additional successive InSAR observations, meaning that the failure date would not have been reliably predicted based on the precursory deformation observed at location 6 in track 53 . The corresponding location 3 in track 155 shows similar behaviour in that a correct timing prediction was initially possible as early as 44 days before the collapse, but then not when the next successive InSAR observation is considered. However, a reliable 

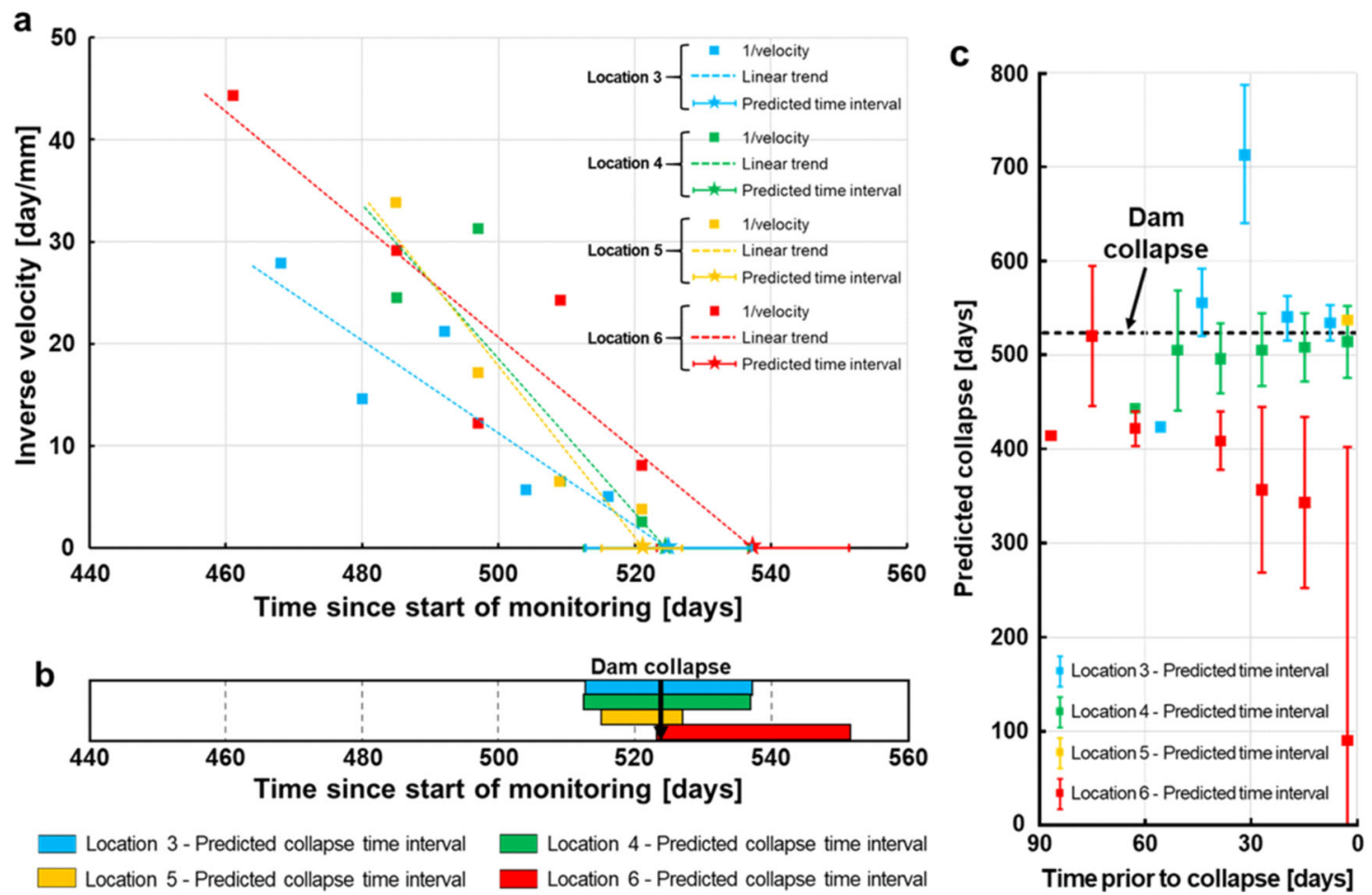

Location 3 - Predicted collapse time interval

Location 4 - Predicted collapse time interval

Location 5 - Predicted collapse time interval

Location 6 - Predicted collapse time interval

Time prior to collapse [days]

Fig. 3 Predicting the timing of the Brumadinho tailings dam collapse. a Inverse velocity analysis for final movement phase exhibited at locations $3,4,5$ and 6 (see Fig. 2). b Predicted time interval for the collapse for locations 3, 4, 5 and 6 in relation to the timing of the dam collapse (indicated by black arrow). c Sensitivity analysis of the predicted collapse time interval for locations 3, 4, 5 and 6 based on inverse velocity analysis of successive velocity measurements made during the period of movement approaching the dam collapse. The time shown in $\mathbf{a}, \mathbf{b}$ and predicted collapse interval in $\mathbf{c}$ corresponds the number of days since the initial InSAR measurement (19 August 2017). Horizontal dashed black line in c represents the timing of the dam collapse.

prediction of the correct timing again becomes possible from 20 days before the failure. At location 5, the accelerated displacement occurred suddenly between the last two Sentinel-1 observations acquired just 3 days before the actual dam collapse. These two observations alone enable a prediction date of within 2 weeks of the actual failure. Location 4 offers the most conclusive evidence of precursory deformation indicative of the occurrence of a collapse, with correct failure date predictions that could have been reliable made as early as 51 days prior (from 5 December 2018). When considered together, the variation in the predictions attests the importance of monitoring deformation over the whole dam structure, rather than focussing on specific areas (e.g., only the dam wall), in addition to utilising multiple SAR viewing geometries where available. Nonetheless, at all of the locations analysed (i.e., locations 3-6), the data points toward a potential failure of the dam.

If implemented as part of a comprehensive operational earlywarning system, a systematic inverse velocity analysis producing three overlapping failure time intervals for the same or different locations on the dam would likely be cause to flag a potential issue with its stability. The data suggest that this would have occurred 44 days before the collapse occurred (Fig. 3c), offering 40 days of notice between when this third overlapping prediction was made and the beginning of its respective failure time interval. Even when factoring in the 1 day of ISBAS processing time currently required to update the displacement time-series once a new SAR acquisition is performed, this is still likely to have been adequate notice for appropriate action to have been taken-whether that be implementing more detailed monitoring using different types of sensor or other mitigation measures.
Dam monitoring implications. Concerns regarding the stability of other upstream dams in the region have since been raised, including that of the Sul Superior dam at the Gongo Soco mine in Barão de Cocais. The area was evacuated as a precautionary measure on 8 February 2019 following concerns that movement detected on the northern pit wall of the mine may subsequently affect the stability of the inactive dam $1.5 \mathrm{~km}$ away ${ }^{27}$. We applied InSAR analysis to the SAR data for the single Sentinel-1 track covering this area, which revealed evidence of downslope motion (an average rate of $<15 \mathrm{~mm} /$ year) along the northern and northwestern walls of the pit (location $\mathrm{W}$ ) during the past 2 years (Fig. 4a). After an initial phase of motion followed by 4 months of relative stability, movement was re-initiated on the slope in December 2018 concurrent with a period of intense rainfall (Fig. 4b). Fragments of the northern pit wall were reported to have slid into the pit on 31 May 2019 (ref. ${ }^{28}$ ), however, our results show continued motion of parts of the northern wall and most of the northwestern wall into early June 2019. Deformation of the Sul Superior dam is also detected, with similar rates of displacement observed on both the tailings beach and dam wall at locations Y and Z, respectively (Fig. 4a). The dam as a whole appears be deforming uniformly and the deformation trends observed are consistent with consolidation settlement, showing a reducing rate of movement with time (Fig. 4b). Additionally, the spoil heap behind the dam (location X) also appears to be subject to settlement (Fig. 4), albeit at a higher average rate (up to -15 $\mathrm{mm} /$ year) than that of the dam and tailings. The uniform rate and pattern of settlement observed at Sul Superior is in contrast to the differential deformation observed prior to the collapse of Dam I, which suggests no apparent degradation of the stability conditions of the Sul Superior dam during June 2017-June 2019. 

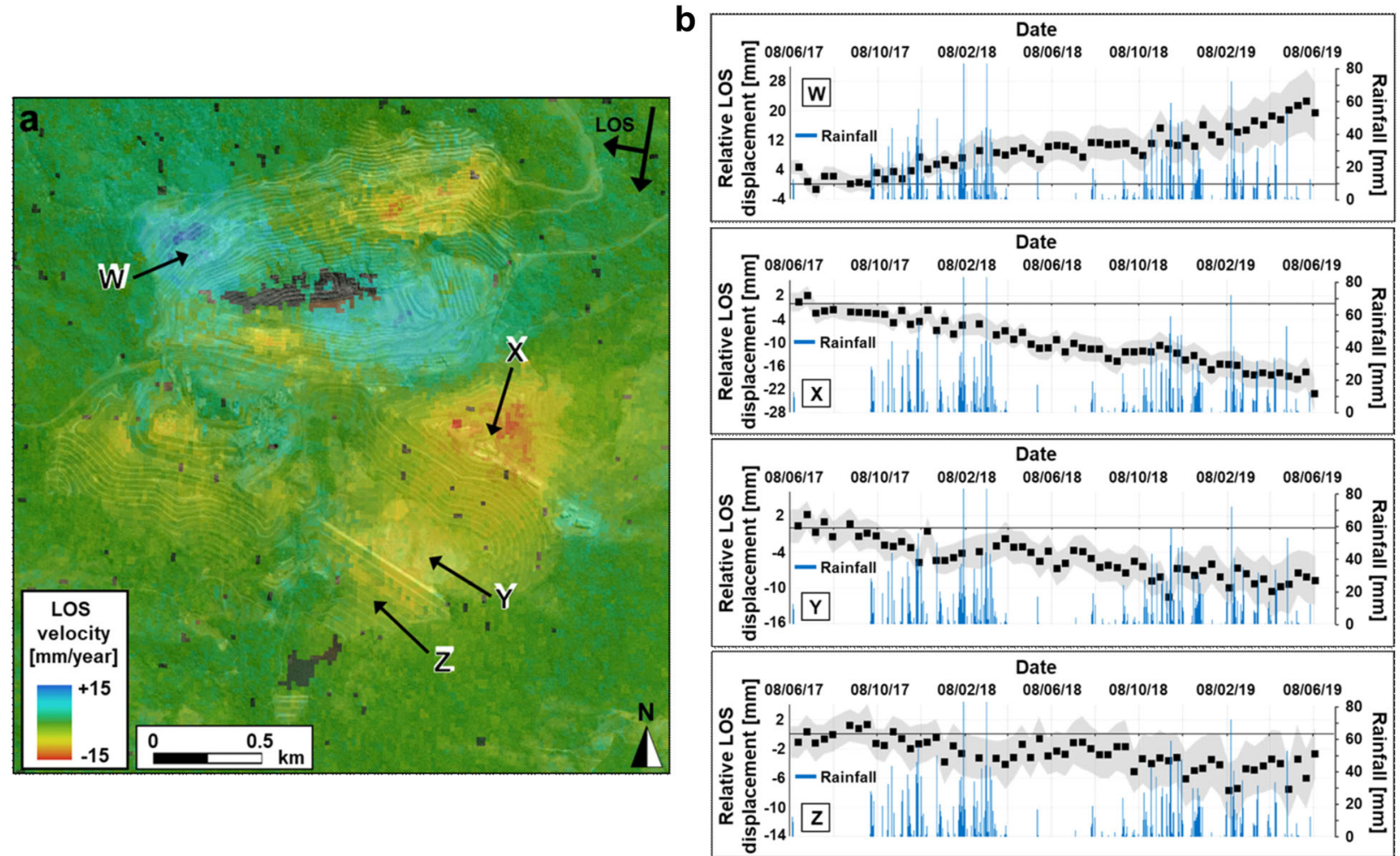

Fig. 4 Deformation of the Sul Superior tailings dam at the Gongo Soco mine, Barão de Cocais $\left(19.96^{\circ} \mathrm{S}, 43.60^{\circ} \mathrm{W}\right)$. a InSAR-derived average line-ofsight (LOS) rate of ground surface deformation for June 2017-June 2019. Negative LOS velocities indicate motion away from the satellite. $\mathbf{b}$ Time-series of mean LOS displacement at locations W-Z indicated on $\mathbf{a}$, and daily rainfall. Negative LOS displacement indicates motion away from the satellite. Grey shading represents the cumulative uncertainty of the standard error of the ISBAS solutions plus the standard deviation of the LOS displacements observed at each location. Basemap image (c) 2020 Maxar Technologies.

Nevertheless, continuous ongoing monitoring of the dam is imperative for detecting any changes in its deformation and future stability.

While monitoring the stability of tailing dams is vital for avoiding catastrophic loss of life and livelihood, their vast extents can pose practical engineering challenges in monitoring them using traditional geotechnical techniques ${ }^{21}$. Although not a standalone monitoring technique, satellite InSAR has been incorporated into integrated monitoring programmes in recent years to develop more cost-effective means of monitoring dams and assist early-warning systems ${ }^{29}$. A key benefit of exploiting satellite InSAR is that it can provide widespread coverage to compliment the often limited discrete point measurements acquired using ground-based techniques, and indeed our results attest the necessity for monitoring the entire tailings dam structure. However, the use of satellite InSAR for monitoring dam stability is restricted to relatively slow rates of deformation, since sudden collapses can cause loss of coherence, the introduction of phase ambiguity, or occur on a time-scale shorter than the revisit time of the satellite ${ }^{25}$. The presence of water on the tailings beach or vegetation can also affect coherence and therefore limit the density and spatial distribution of displacement measurements that can be obtained; the effect of the latter has been shown here to be particularly limiting for conventional InSAR techniques. Nonetheless, through the application of the advanced ISBAS InSAR technique in conjunction with freely available Sentinel-1 imagery, we have demonstrated the potential to perform detailed deformation monitoring over dry, vegetated tailings dams in a cost-effective manner. Moreover, this was achieved without the need for ground infrastructure, meaning that such an approach can be utilised independently by mine operators, regulators or any third party to help support the monitoring of any site around the world. Where stereo analysis is not possible due to an absence of orbit tracks with sufficiently different viewing geometries, a SAR image stack acquired with a small angle of incidence is recommended due to the increased sensitivity to vertical deformations.

The application of an advanced InSAR technique has provided valuable insight into precursory deformation prior to the collapse of Dam I at Brumadinho on 25 January 2019. We observed widespread deformation across the dam wall and tailings from two independent satellite tracks, revealing areas subject to consolidation settlement. However, in contrast to attempts using other InSAR techniques, we also detected evidence of anomalous deformation not consistent with consolidation on the dam wall and tailings beach, instead exhibiting a clear accelerated rate of deformation from about late October 2018 following a period of increased rainfall. An empirical approach based on the inverse velocity at these locations enabled correct predictions of the time interval for the collapse of the dam, which demonstrates the importance of monitoring deformation over the entire tailings dam instead of solely the dam wall. We analysed a similar dam thought to be at risk of collapse and found that it does not currently exhibit the same anomalous pre-failure deformation behaviour as Dam I, instead showing characteristics of consolidation settlement.

\section{Methods}

InSAR data and analysis. We mapped deformation of the Brumadinho Dam I using SAR imagery acquired from the Sentinel-1 mission. In the absence of 
coverage from an ascending orbit, the deformation was investigated using data acquired from two overlapping descending orbit tracks (tracks 53 and 155) covering approximately the same time period. The track 53 dataset consisted of 45 images acquired from 12 August 2017 to 22 January 2019 at an incidence angle of $32^{\circ}$ measured from the vertical. The track 155 dataset comprised 45 images acquired between 7 August 2017 and 17 January 2019 at an incidence angle of $45^{\circ}$. Both datasets were processed independently with the ISBAS technique ${ }^{13}$. The ISBAS technique, invented in 2012, is an adapted version of the established lowresolution SBAS Differential InSAR (DInSAR) time-series algorithm ${ }^{30,31}$. It was designed to improve the density and spatial distribution of survey points to return measurements in vegetated areas, where conventional DInSAR processing algorithms habitually struggle due to incoherence ${ }^{12,32}$. The ISBAS algorithm is implemented using Terra Motion Limited's in-house Punnet software, which covers all aspects of processing from the co-registration of Single Look Complex (SLC) data to the generation of time-series ${ }^{33}$. Phase unwrapping was implemented using an in-house implementation of the Statistical-cost, Network-flow Algorithm for Phase Unwrapping (SNAPHU) algorithm ${ }^{34}$. Measurements in each case were calculated relative to a reference point situated in an urban area; for Brumadinho Dam I, the same reference point in the town of Brumadinho was used for both tracks. Using restrictions on maximum orbital and temporal baselines of $100 \mathrm{~m}$ and 1 year, respectively, average LOS velocities (Fig. 1) and displacement time-series (Fig. 2) for each pixel were derived at a spatial resolution of $20 \mathrm{~m}$, according to the previously described approaches ${ }^{13,35}$, using a multilook factor of $7 \times 2$ pixels. All outputs were geocoded to a Universal Transverse Mercator (UTM) projection using the Shuttle Radar Topography Mission (SRTM) digital elevation model $(\mathrm{DEM})^{36}$. There were small inconsistencies in geolocation over the mines due to the age of the SRTM DEM, created in 2000, manifesting themselves as a slight difference in the shape of the lake extent between satellite tracks. No smoothing was applied as part of the processing; however, the velocity and displacement maps shown (Figs.1b, c, 2a, b, 4a and Supplementary Fig. 3) were smoothed using a $3 \times 3$ pixel averaging filter for the sole purpose of aiding visual interpretation. A combination of this filtering and slight differences in the accuracy of the orthorectification is responsible for the apparent differences in coverage between the two tracks-e.g., the inconsistent shape of the lake on the neighbouring tailings dam.

Pixels were processed only if they met an average coherence threshold of 0.45 . As discussed in Cigna and Sowter ${ }^{31}$, the standard error of the velocity, $e_{i}$, is related to the number of best coherence interferograms used, $n_{i}$, and can be modelled as:

$$
e_{i}=\frac{11}{\sqrt{n_{i}}} \mathrm{~mm} / \text { year. }
$$

Short baseline pairs generally produced very good interferograms over the dam and examples are shown in Supplementary Figs. 4 and 5. The ISBAS method uses good-quality phases only for the measurement of displacement. For tracks 53 and 155 over the Brumadinho Dam I, $n_{i}$ was set to be a minimum of 430 and 498 interferograms, respectively, meaning that the standard error in the LOS was always better than $0.53 \mathrm{~mm} / \mathrm{year}$. Maps of the number of best coherence interferograms $\left(n_{i}\right)$ for the two tracks are shown in Supplementary Fig. 6. For Sul Superior, $n_{i}$ was 720 meaning for that site the maximum standard error is even better at $0.41 \mathrm{~mm} /$ year.

An ISBAS stereo analysis of the two Brumadinho time-series stacks was attempted ${ }^{37}$, with modifications to account for the same-side geometry and alongtrack directions associated with tracks 53 and 155 . Firstly, given the 5-day offset on acquisitions between the two tracks, a linear temporal interpolation was applied to ensure that the dates coincided. Next, we performed the 2-D stereo analysis on the two time-series, on a date-by-date basis, to derive displacements in the vertical up-down $\left(d_{\mathrm{UD}}\right)$ and lateral towards-away across-track $\left(d_{\mathrm{TA}}\right)$ directions as given by:

$$
\begin{aligned}
& d_{\mathrm{UD}}=\left(\mathrm{LOS}_{53} \times \sin \theta_{155}-\mathrm{LOS}_{155} \times \sin \theta_{53}\right) / \sin \left(\theta_{155}-\theta_{53}\right), \\
& d_{\mathrm{TA}}=\left(\mathrm{LOS}_{155} \times \cos \theta_{53}-\mathrm{LOS}_{53} \times \cos \theta_{155}\right) / \sin \left(\theta_{155}-\theta_{53}\right),
\end{aligned}
$$

where $\mathrm{LOS}_{53}$ and $\mathrm{LOS}_{155}$ are the LOS displacements measured from tracks 53 and 155 , and $\theta_{53}$ and $\theta_{155}$ are the incidence angles for tracks 53 and 155. Given the small difference between the incidence angles, the precision in the up-down and towards-away directions is $2-3$ times worse than in the LOS directions (although slightly better in up-down than towards-away). Thus, the stereo analysis undertaken here is only useful for detecting relatively large displacements. It was not feasible to resolve directly into the east-west direction as the geometry between the observations is almost identical in this case. However, as the angle of climb of the Sentinel- 1 orbit is less than $10^{\circ}$ at this latitude, we therefore assume that the lateral towards-away motion is entirely in the east-west direction. The results of the stereo analysis for the Brumadinho dam are shown in Supplementary Fig. 3.

For the Sul Superior dam site, Sentinel-1 imagery was only available from a single track (track 155) from a descending orbit. A total of 59 images were available for 8 June 2017 to 10 June 2019. The data were processed according to the approach outlined above, using the ISBAS technique and the same orbital and temporal baseline limits as the Brumadinho Dam I site to derive average LOS velocities and time-series for each pixel (Fig. 4).

With the aim of detecting and characterising any anomalous precursory deformation that occurred prior to the collapse, the entire InSAR time-series data for each track were closely inspected. This was performed by first dividing the dam into sectors representing its main structural elements (e.g., dam wall, front part of the tailings beach, rear of the tailings beach $)^{9}$ and then systematically inspecting the time-series data to identify locations exhibiting distinctive deformation within each sector. Representative time-series for these locations were then obtained by averaging the individual time-series for a subset of 25-208 contiguous pixels within the locality, depending on the spatial extent and uniformity of the respective deformation pattern. The uncertainty associated with each average deformation time-series was then computed as the accumulation of the standard deviation of the subset time-series at each location, plus the maximum standard error of the ISBAS solutions associated with the respective track.

Alongside ISBAS, we also implemented two additional InSAR techniques over the Brumadinho Dam I site. Firstly, for comparison, we performed standard coherent scatterer analysis on tracks 53 and 155 to extract average LOS velocities using a conventional SBAS time-series approach (Supplementary Fig. 2), following Berardino et al. ${ }^{35}$. The SBAS processing is the same as for ISBAS except that only pixels meeting the coherence threshold of 0.45 throughout the entire stack are considered. A disadvantage of all multi-temporal DInSAR approaches-including ISBAS-is the limited maximum rate of deformation that they are able to measure due to the inherent interferometric phase ambiguity ${ }^{20}$. Therefore, to complement the ISBAS results, we also implemented a DInSAR stacking technique to help identify fast deformation over the dam. This technique uses differential interferograms generated using only consecutive image pairs in order to maximise temporal coherence. The consecutive-pair interferograms are filtered using the modified Goldstein filter ${ }^{38}$ in the computation of average LOS velocities and the displacement time-series (Supplementary Fig. 1).

Daily rainfall data. Rainfall data for the Brumadinho and Sul Superior sites were obtained from the Brazilian National Institute of Meteorology (INMET). For each site, we sourced available data from the nearest automatic meteorological station, which, for Brumadinho was located $15 \mathrm{~km}$ away in Ibirité (Rola Moca-A555), and for Sul Superior was located $38 \mathrm{~km}$ away in Belo Horizonte (Cercadinho-F501). The rainfall data from these weather stations was summed to generate daily rainfall totals $(\mathrm{mm})$ for direct comparison with the InSAR deformation time-series.

Temporal prediction of the dam collapse. The timing of the failure of Dam I at Brumadinho was estimated using the well-established inverse velocity method $24,26,39-41$, which involves fitting a straight line to inverse velocity values that decrease over time to zero on the approach to a slope collapse. To achieve this the velocities at each time point were computed from the change in displacement observed between successive InSAR observations made at 12-day intervals. In order to reduce the effect of noise on the timing prediction, the time-series of LOS velocities were smoothed by applying a 3-point moving average filter prior to the calculation of the inverse velocities ${ }^{25}$. Inverse velocities were only computed for deformation time-series exhibiting accelerated deformation (Fig. 2; locations 3, 4, 5 and 6), and only for the observations constituting the final movement phase on the approach to the failure ${ }^{26}$. The inverse velocities were then plotted against time in days after the initial InSAR measurement (19 August 2017) and linear regression was used to establish the best-fit straight line, with the extrapolated intercept on the time-axis indicating the predicted timing of the collapse (Fig. 3a). Determining whether the failure could have been correctly predicted is dependent on the number of observations used in the regression analysis. Therefore, to increase the objectivity of the regression analysis, we follow the same approach as Carlà et al. ${ }^{25}$, by using the consecutive inverse velocities preceding the collapse that produced the highest coefficient of determination, $R^{2}$-which ranged between four and five data points. By also employing the same logic of Carlà et $\mathrm{al} .^{25}$, any anomalous data points clearly affected by either phase wrapping or noise were discarded from the regression analysis; this resulted in the removal of only a single point for location 6 . Time intervals for the estimated collapse date (Fig. 3b) were computed using the standard error associated with each regression.

We also undertook a sensitivity analysis to determine how early and reliably a correct collapse date could have been predicted using the systematic Sentinel-1 InSAR observations, by iteratively performing the regression analysis for an increasing number of successive inverse velocity measurements obtained during the final movement phase at each location (Fig. 3c). In each case, the onset of the final movement phase was identified as the point in the time-series at which there was a marked acceleration in the deformation. For location 5, the duration of this final phase of increased displacement was short, only spanning the two Sentinel-1 observations acquired just before the actual dam collapse.

\section{Data availability}

The hourly meteorological data are freely available to download for the Ibirite (Rola Moça-A555) station at https://tempo.inmet.gov.br/GraficosAnuais/A555 and the Belo Horizonte (Cercadinho-F501) station at https://tempo.inmet.gov.br/GraficosAnuais/ F501. The Sentinel-1 datasets are freely available and can be obtained by searching and downloading the Interferometric Wide (IW) swath mode products for orbit track numbers 53 and 155 through the Copernicus Open Access Hub (https://scihub. copernicus.eu/dhus/\#/home). The processed interferometric data and deformation maps are commercially sensitive and may be made available on reasonable request by email addressed to the corresponding author (S.G.). Additional data that support the findings of this study are available at https://data.mendeley.com/datasets/pf9x7375vd/1. 


\section{Code availability}

InSAR data were processed using the Punnet software (Terra Motion Limited). Deformation maps contained within the figures were created with the aid of ArcMap ${ }^{\text {tw }}$ (Copyright $\odot$ Esri. All rights reserved)

Published online: 04 January 2021

\section{References}

1. Porsani, J. L., de Jesus, F. A. N. \& Stangari, M. C. GPR survey on an iron mining area after the collapse of the tailings Dam I at the Córrego do Feijão Mine in Brumadinho-MG, Brazil. Remote Sens. 11, 860 (2019).

2. Vale. Vale updates information on the dam breach in Brumadinho. http:// www.vale.com/EN/investors/information-market/Press-Releases/Pages/ Vale-updates-information-on-the-dam-breach-in-Brumadinho.aspx (2019).

3. Silveira, F. A. O., Gama, E. M., Dixon, K. W. \& Cross, A. T. Avoiding tailings dam collapses requires governance, partnership and responsibility. Biodivers. Conserv. 28, 1933-1934 (2019).

4. de Carvalho, G. Video shows the exact time when Vale dam breaks in Brumadinho. G1 Minas Gerais; https://g1.globo.com/google/amp/mg/minasgerais/noticia/2019/02/01/video-mostra-o-momento-exato-em-que-barragemda-vale-rompe-em-brumadinho.ghtml (2019).

5. Robertson, P. K., de Melo, L., Williams, D. J. \& Wilson, G. W. Report of the expert panel on the technical causes of the failure of Feijão Dam I. http://www. bltechnicalinvestigation.com/ (2020).

6. Riedmann, M., Anderssohn, J. \& Lang, O. Monitoring of slope stability of tailings dams in South Africa using satellite interferometry. In Proc. XXIVth Geological Remote Sensing Group Annual General Meeting (Berlin, Germany, 2013).

7. Necsoiu, M. \& Walter, G. R. Detection of uranium mill tailings settlement using satellite-based radar interferometry. Eng. Geol. 197, 267-277 (2015).

8. Holden, D., Donegan, S. \& Pon, A. Brumadinho Dam InSAR study: analysis of TerraSAR-X, COSMO-SkyMed and Sentinel-1 images preceding the collapse. In Proc. 2020 International Symposium on Slope Stability in Open Pit Mining and Civil Engineering (ed. Dight, P. M.) 293-306 (Australian Centre for Geomechanics, 2020).

9. Silva Rotta, L. H. et al. The 2019 Brumadinho tailings dam collapse: possible cause and impacts of the worst human and environmental disaster in Brazil. Int. J. Appl. Earth Obs. Geoinf. 90, 102119 (2020).

10. Du, Z. et al. Risk assessment for tailings dams in Brumadinho of Brazil using InSAR time series approach. Sci. Total Environ. 717, 137125 (2020).

11. Crosetto, M., Monserrat, O., Iglesias, R. \& Crippa, B. Persistent scatterer interferometry: potential limits and initial C- and X-band comparison. Photogramm. Eng. Remote Sens. 76, 1061-1069 (2010).

12. Osmanoğlu, B., Sunar, F., Wdowinski, S. \& Cabral-Cano, E. Time series analysis of InSAR data: methods and trends. ISPRS J. Photogramm. Remote Sens. 115, 90-102 (2016).

13. Sowter, A., Bateson, L., Strange, P., Ambrose, K. \& Syafiudin, M. DInSAR estimation of land motion using intermittent coherence with application to the South Derbyshire and Leicestershire coalfield. Remote Sens. Lett. 4, 979-987 (2013).

14. Gee, D., Sowter, A., Novellino, A., Marsh, S. \& Gluyas, J. G. Monitoring land motion due to natural gas extraction; validation of the Intermittent SBAS (ISBAS) DInSAR algorithm over gas fields of North Holland, the Netherlands. Mar. Pet. Geol. 77, 1338-1354 (2016).

15. Zebker, H. A., Rosen, P. A. \& Hensley, S. Atmospheric effects in interferometric synthetic aperture radar surface deformation and topographic maps. J. Geophys. Res. 102, 7547-7563 (1997).

16. Sandwell, D. \& Price, E. Phase gradient approach to stacking interferograms. J. Geophys. Res. 103, 30183-30204 (1998).

17. Wright, T., Parsons, B. \& Fielding, E. Measurement of interseismic strain accumulation across the North Anatolian Fault by satellite radar interferometry. Geophys. Res. Lett. 28, 2117-2120 (2001).

18. Armaş, I., Mendes, D. A., Popa, R.-G., Gheorghe, M. \& Popovici, D. Longterm ground deformation patterns of Bucharest using multi-temporal InSAR and multivariate dynamic analyses: a possible transpressional system? Sci. Rep. 7, 43762 (2017).

19. Gee, D. et al. Ground motion in areas of abandoned mining: application of the Intermittent SBAS (ISBAS) to the Northumberland and Durham coalfield, UK. Geosciences 7, 85 (2017).

20. Crosetto, M., Monserrat, O., Cuevas-González, M., Devanthéry, N. \& Crippa, B. Persistent scatterers interferometry: a review. ISPRS J. Photogramm. Remote Sens. 115, 78-89 (2016).
21. Hu, X., Oommen, T., Lu, Z., Weng, T. \& Kim, J.-W. Consolidation settlement of Salt Lake County tailings impoundment revealed by time-series InSAR observations from multiple radar satellites. Remote Sens. Environ. 202, 199-209 (2017).

22. Sowter, A. The automatic extraction of DEM data from stereo RADARSAT pairs over the tropics. ISPRS Arch. 32, 291-298 (1998).

23. Toutin, T. \& Gray, L. State-of-the-art of elevation extraction from satellite SAR data. ISPRS J. Photogramm. Remote Sens. 55, 13-33 (2000).

24. Fukuzono, T. A new method for predicting the failure time of a slope. In Proc IVth International Conference and Field Workshop on Landslides (Tokyo, Japan, 1985).

25. Carlà, T. et al. Perspectives on the prediction of catastrophic slope failures from satellite InSAR. Sci. Rep. 9, 14137 (2019).

26. Royán, M. J., Abellán, A. \& Vilaplana, J. M. Progressive failure leading to the 3 December 2013 rockfall at Puigcercós scarp (Catalonia, Spain). Landslides 12, 585-595 (2015).

27. Vale. Vale clarifies on the Gongo Soco mine. http://www.vale.com/EN/aboutvale/ reports/atualizacoes_brumadinho/Pages/mina-gongo-soco.aspx (2019).

28. Vale. Vale updates on Gongo Soco Mine slope movement. http://www.vale. com/EN/aboutvale/news/Pages/vale-updates-on-gongo-soco-mine-slopemovement.aspx (2019).

29. Ruiz-Armenteros, A. M. et al. Deformation monitoring of dam infrastructures via spaceborne MT-InSAR. The case of La Viñuela (Málaga, southern Spain). Procedia Comput. Sci. 138, 346-353 (2018).

30. Bateson, L., Cigna, F., Boon, D. \& Sowter, A. The application of the Intermittent SBAS (ISBAS) InSAR method to the South Wales Coalfield, UK. Int. J. Appl. Earth Obs. Geoinf. 34, 249-257 (2015).

31. Cigna, F. \& Sowter, A. The relationship between intermittent coherence and precision of ISBAS InSAR ground motion velocities: ERS-1/2 case studies in the UK. Remote Sens. Environ. 202, 177-198 (2017).

32. Gong, W. et al. Comparison of small baseline interferometric SAR processors for estimating ground deformation. Remote Sens. 8, 330 (2016).

33. Sowter, A. et al. Mexico City land subsidence in 2014-2015 with Sentinel-1 IW TOPS: results using the Intermittent SBAS (ISBAS) technique. Int. J. Appl. Earth Obs. Geoinf. 52, 230-242 (2016).

34. Chen, C. W. \& Zebker, H. A. Two-dimensional phase unwrapping with use of statistical models for cost functions in nonlinear optimization. J. Opt. Soc. Am. A 18, 338-351 (2001)

35. Berardino, P., Fornaro, G., Lanari, R. \& Sansosti, E. A new algorithm for surface deformation monitoring based on small baseline differential SAR interferograms. IEEE Trans. Geosci. Remote Sens. 40, 2375-2383 (2002).

36. Farr, T. G. et al. The Shuttle Radar Topography Mission. Rev. Geophys. 45, 1-43 (2007)

37. Pepe, A. \& Calò, F. A review of interferometric synthetic aperture RADAR (InSAR) multi-track approaches for the retrieval of Earth's surface displacements. Appl. Sci. 7, 1264 (2017).

38. Baran, I., Stewart, M. P., Kampes, B. M., Perski, Z. \& Lilly, P. A modification to the Goldstein radar interferogram filter. IEEE Trans. Geosci. Remote Sens. 41, 2114-2118 (2003)

39. Carlà, T. et al. Guidelines on the use of the inverse velocity method as a tool for setting alarm thresholds and forecasting landslides and structure collapses. Landslides 14, 517-534 (2017).

40. Carlà, T., Farina, P., Intrieri, E., Botsiala, K. \& Casagli, N. On the monitoring and early-warning of brittle slope failures in hard rock masses: examples from an open-pit mine. Eng. Geol. 228, 71-81 (2017).

41. Carlà, T. et al. Displacement of a landslide retaining wall and application of an enhanced failure forecasting approach. Landslides 15, 489-505 (2018).

\section{Acknowledgements}

This work was supported by the GeoEnergy Research Centre and by the Engineering and Physical Sciences Research Council through the ACHILLES project (grant number EP/ R034575/1). We are grateful to the Copernicus programme and INMET for making Sentinel-1 data and rainfall data freely available.

\section{Author contributions}

A.S. and S.G. formulated the study concept. A.S., D.G., A.A. and R.G. contributed to the InSAR processing. S.G. performed the data analysis. S.G., A.S., J.G. and D.T. contributed to the data interpretation and led the writing of the manuscript. All authors participated in manuscript editing and final approval.

\section{Competing interests}

The authors declare the following competing interests: A.S., J.G., D.G., A.A. and R.G. are affiliated with Terra Motion Limited. The ISBAS method is owned by the University of Nottingham and is the subject of a UK Patent Application (No. 1709525.8) with the inventor named as Dr. Andrew Sowter; it is currently Patent Pending. 


\section{Additional information}

Supplementary information is available for this paper at https://doi.org/10.1038/s43247020-00079-2.

Correspondence and requests for materials should be addressed to S.G.

Peer review information Primary handling editor: Joe Aslin.

Reprints and permission information is available at http://www.nature.com/reprints

Publisher's note Springer Nature remains neutral with regard to jurisdictional claims in published maps and institutional affiliations. (c) (1) Open Access This article is licensed under a Creative Commons Attribution 4.0 International License, which permits use, sharing, adaptation, distribution and reproduction in any medium or format, as long as you give appropriate credit to the original author(s) and the source, provide a link to the Creative Commons license, and indicate if changes were made. The images or other third party material in this article are included in the article's Creative Commons license, unless indicated otherwise in a credit line to the material. If material is not included in the article's Creative Commons license and your intended use is not permitted by statutory regulation or exceeds the permitted use, you will need to obtain permission directly from the copyright holder. To view a copy of this license, visit http://creativecommons.org/ licenses/by/4.0/.

(C) The Author(s) 2021 